\title{
Managing IT Projects in Public Companies: A Case Study
}

\author{
Abdelghani Bouras ${ }^{1}$ and Salaheddine Bendak ${ }^{2}$ \\ ${ }^{1}$ Associate Professor, Dept. of Industrial Engineering, King Saud University, PO Box 800 Riyadh 11421 Kingdom of \\ Saudi Arabia. Phone: +966-1-4676831; Fax: +966-1-4676831, Email: bouras@ksu.edu.sa \\ ${ }^{2}$ Associate Professor, Dept. of Industrial Engineering and Engineering Management, University of Sharjah, PO Box \\ 27272 Sharjah United Arab Emirates. Phone: +971-3-5053918; Fax: +971-3-5053963, Email: sbendak@ sharjah.ac.ae \\ (corresponding author).
}

\author{
Project Management \\ Received on January 1, 2013; Revisions July 15, 2013; July 29, 2013; Accepted on August 23, 2013 \\ Available online November 15, 2013
}

\begin{abstract}
As part of its public sector modernization effort, a North African government has put a lot of effort and allocated significant budgets since 1997 to modernize one of its main public sector companies. Consequently, this company, that mainly offers postal services, initiated many IT-based projects to computerize all paper-based ongoing services offered through its branches and to present new products to customers. This company was aiming to improve service quality and to diversify the range of its services. However, some of these IT-based projects inevitably faced problems. Some projects were either not completed successfully, cancelled, over-budget or taking more time than scheduled. As a result, many employees and customers of this company were dissatisfied and complained about bad planning, slowness and significant disruptions in these projects, an event that affected adversely the quality of service. This study aims at determining the causes of these project disruptions, failures or delays. To achieve this aim, 30 experienced project developers and engineers working in that company's IT department volunteered to respond to a detailed questionnaire specifically developed for this purpose. The questionnaire included questions about project vision clarity, time/cost management, project quality assurance, risk management and human resources management. Results show that the main reasons for disruptions, failure or delays in IT projects are lack of business plan and poor documentation during and after finishing projects, lack of clear quality assurance criteria, standards and reviews, and poor project risk management practices. Ramifications of such results in terms of improving IT project management practices in the public service sector are finally presented.
\end{abstract}

Keywords: IT projects, applications development, questionnaire, descriptive statistics.

\section{Introduction}

Success in managing projects is perceived in different ways by different stakeholders. An IT project might seem successful to some but unsuccessful to others according to their vested interests, especially in the absence of clear and commonly accepted key performance indicators (Bryde and Brown, 2005; Toor and Ogunlana, 2010). This problem is even more obvious in public sector projects where the number of stakeholders is usually bigger (Cox et al., 2003). Information technology (IT) projects are particularly challenging due to the rapid and continuous developments in this area (Sauer and Reich, 2009).

After being elected to lead one of the North African countries just before the end of the twentieth century, the new government of that time launched an economic program that aimed at improving both public sector performance and private-sector-led growth. As one of its strategies to generate sustainable growth, reforms were initialized to modernize postal services through the increased use of modern means of information technology. Creation of a wide range of IT-based postal services and the dissemination of information technologies would make the economy more competitive, bring them closer to international markets and open mutually urban and rural areas to new business opportunities.

Accordingly, the government launched an ambitious program of sector policy reforms; a new law on postal services was promulgated. It initiated an action plan for IT development, with key priorities to promote the use of IT both in the public and private sectors and to create an enabling environment for the growth of IT-related activities. The government adopted a strategy to improve performance of both postal and financial services delivered by post offices. It aimed also at modernising the legal and institutional framework to improve efficiency in a progressively competitive environment while keeping its monopoly on some basic postal operations such as international courier and parcel delivery in urban areas. Specifically, that country's postal services management has put three targets: improve service quality, increase customer satisfaction and raise productivity. 
The potential for expanding the range of available services to more customers is huge, especially for businesses. It is important to point out that there is still a significant percentage of the population in the countryside that does not have access to postal pick-up and delivery nor access to electronic and traditional postal services like cyber post and fax. However, by offering different and qualified services, this market position presents good opportunities for post offices.

Based on information solicited from the company, several new IT projects were launched in recent years to:

1. Computerise and modernise the ongoing paperbased services offered through its post office.

2. Present new products in order to diversify the range of services offered to satisfy evolving and existing customer needs.

In fact, diversification and expansion of offered services are notable. However and at the same time, productivity gains and quality improvements are still modest with widespread customer and employee dissatisfaction with the quality of service reported regularly in newspaper articles, radio talk back shows and TV programs. Comments like "the service was much better when it was operated manually" can be heard or read regularly.

Employees confirm that even though they have the required technical skills, problems adversely affect their performance, lead to misjudge their efforts and limit their output. In short, there is consensus among many stakeholders that there are severe problems in managing IT projects. If solutions are not found for these problems quickly, this situation has the potential to harm the organisation's brand image and cause loss of loyalty among its customers, especially with the continuous appearance of new competitors for both postal and financial services. This might have adverse effects on the future of the company as a whole. Therefore, pinpointing the problems is necessary to redefine project management practices and define a new management mindset to ensure achieving long term objectives (Sauer and Reich, 2009).

\section{Background}

Extensive research conducted by international consulting companies (such as Gartner and Forrester) reveal that the success of a project is directly related to the quality of managing and leading its resources (i.e. time, money, materials and labour) for achieving the objectives. These studies have shown also that just one third of projects, including IT projects, are completed successfully and on time. The remaining two thirds fail or are completed late and/or overbudget. It is concluded that the use of adequate managerial tools and key performance indicators cannot ensure the success of every project, yet it can have an effect on moving the project from failure to success (ETR, 2004; Toor and Ogunlana, 2010).

Standish Group International (2004) studied the outcome of approximately 30000 IT projects. In Table 1, outcome of these projects is given. From Table 1, it is clear that most projects still have an unsatisfactory outcome and that the risk of failure or exceeding the time or the budget allocated is very high.
Table 1: Project outcome of 30000 IT projects

\begin{tabular}{cc}
\hline Project Outcome & Rate \\
\hline Late completion (of original time estimate) & $222 \%$ \\
Overbudget rate (of original cost estimate) & $189 \%$ \\
Success rate (on time and on budget) & $16 \%$ \\
Failure rate & $31 \%$ \\
\hline
\end{tabular}

Nevertheless, risk and opportunity go hand in hand. Many projects strive to advance current capabilities and achieve something that hasn't been done before. The opportunity for advancement cannot be achieved without taking risk. As Van Scoy (1992) says "Risk in itself is not bad; risk is essential to progress, and failure is often a key part of learning. But we must learn to balance the possible negative consequences of risk against the potential benefits of its associated opportunity". This study aims at assessing potential risk in IT projects in public postal companies while taking a North African country as a case study with the aim of determining causes of failure and minimising the risk of failure.

\section{Research Methodology}

As mentioned before, IT projects faced some serious managerial problems. To investigate this issue, the choice of research strategy should be decided first. The scientific conceptual framework is represented by two different views: Post-positivism and Constructivism. Postpositivism refers to determination, reductionism, empirical observation and measurement and theory verification. Constructivism refers to understanding, multiple participation meanings, social and historical construction and theory generation. Which view a researcher chooses is dependent on personal views on the application of theories in science. Therefore, the investigator either has a framework that he wants to verify or will need to construct it whenever data are collected. Depending on which research methodology the researcher chooses, they have to apply one of the following two research strategies (Creswell, 2003):

1. A quantitative approach is one in which the investigator primarily uses post-positivist claims for developing knowledge (i.e. cause and effect thinking, reduction to specific variables and hypotheses and questions, use of measurement and observation, and the test of theories).

2. A qualitative approach is one in which the inquirer often makes knowledge claims based primarily on constructivist perspectives, qualitative researchers study things in their natural settings, attempting to make sense of or interpret phenomenon in terms of the meanings people bring to them (Denzin and Lincoln, 2000).

Given the fact that the theoretical framework discussed above presents a reference model for this study, a postpositivist methodology is chosen to conduct this study and questions are set in order to compare the discussed scopes with the current practices of the IT department.

Hence, being post-positivist as well as constructive refers to combine both qualitative and quantitative approaches to accomplish this research. A close-ended questionnaire with three predetermined choices (agree, do not agree and do not know) is the tool used for the 
investigation in this study. The sequence and wording of the questions are determined by means of schedule and the researcher is left no freedom to make modifications. It is therefore characterized by being a closed situation (Cohen et al, 2000).

\subsection{Subjects}

The choice of the sample size is fundamental when making a research study. However, the focus in this study was on IT projects. Therefore, researchers decided to concentrate on members of the Information Technology Department who are responsible for implementing new projects and planning for the future of IT in the organisation. Accordingly, relevant managers, engineers and developers were approached to participate in this study. After being briefed on the study, 30 IT professionals agreed to participate in this study. They represented more than half of all IT professionals in the company. Such a sample is also comparable to other published research studies of similar scope (see, for example, Al-Otaibi et al., 2013). Fig. 1 shows the work distribution of those 30 subjects.

\subsection{Questionnaire}

The questionnaire consisted of 24 questions given in Table 2. These questions were grouped under five different scopes as follows:

- vision clarity (6 questions)

- time and cost management (4 questions)

- quality management (6 questions)

- risk management (3 questions)

- human resources management (5 questions)

\section{Results}

In Table 3, a summary of questionnaire answers is given. Numbers represent respectively: percentage of people who did not respond to the questionnaire, percentage of answers that agree with the question, percentage of answers that do not agree, and percent of respondents who answered with "don't know" or where no answer was recorded at all. In Fig. 2, average percentages of answers that agree with questions within each scope (from Table 3 ) are shown.

\section{- Vision Clarity Scope}

Within the vision clarity scope, responses show that $30 \%$ of employees reported that IT projects did not have clear objectives from the beginning based on proper market research. Even a higher percentage (43\%) said that project plans were not documented before the start and a higher percentage $(67 \%)$ said that the team was usually not briefed on project functional characteristic before the start. Moreover, $73 \%$ of respondents said that changes in project content were never documented. Finally, the majority of responses $(77 \%)$ said that they were aware of new IT projects' importance and vitality for the future of the organization while $10 \%$ claimed that they were not aware of that.
With some projects being launched without proper vision or market research, the company might face significant loss in time, effort and money besides the bad impact that issue will have on its workforce morale. Absence of this vision or market research studies has the potential for new products being rejected by customers. Furthermore, most project teams were not provided at the project start with documents which define the product/service characteristics. As a result, developers/engineers might have been facing difficulties in performing their tasks due to this lack of information.

- Time and Cost Management Scope

Within the time and cost management scope, $27 \%$ of respondents claimed that there was usually no clear timeframe or clear budget before starting projects. A slightly higher percentage $(30 \%)$ of respondents said that dividing the project to stages and estimating time and cost of each stage was not a regular practice before starting projects. Moreover, 30\% of respondents claimed that project managers did not or could not keep track of time and cost at all stages. It is worth mentioning here that the department started using a project tracking software recently and that some employees haven't started using it yet. A massive $80 \%$ of respondents stressed that there was no documentation of lessons learnt on project time or budget throughout and after completion of projects for future referral.

One worrying point in this scope is that estimation of duration of project activities depended heavily on the estimator's personal opinion and duration of pervious projects are not usually taken into consideration. This has the potential to inflate these durations.

\section{- Quality Management Scope}

Two thirds of respondents claimed that no clear quality criteria or standards were defined before execution and that there was no monitoring process of quality during project execution. Consequently, no corrective action was taken in the quality management scope. None of the respondents $(0 \%)$ agreed with question 13 . However, $67 \%$ of respondents said that quality assurance reports and checklists are not usually used for quality control and feedback while $30 \%$ did not give any answer which may be interpreted as a lack of information about the process of reporting. $60 \%$ of respondents said that there is no continuous evaluation of all project stages and that all priority was given to completing the project. Half of the respondents said that there was no continuous documentation of quality monitoring criteria. Finally, a massive $70 \%$ of respondents denied any documentation of quality feedback after completing projects. On average, Fig. 2 shows that only $21 \%$ of the employees agree on the questions, which is very low and figure out a weakness in quality of the process.

Responses clearly show that there were serious problems in this scope. These problems have to be addressed if the company is serious in its declared ambition of getting ISO 9001/2007 certification. 


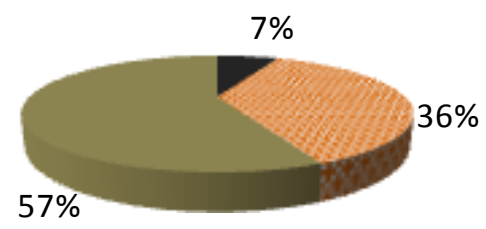

\author{
- Managers \\ Engineers \\ Developers
}

Fig. 1. Work type of people interviewed

Table 2. Questionnaire's scopes and questions

\begin{tabular}{|c|c|}
\hline Issue & Questions \\
\hline \multirow{6}{*}{$\begin{array}{l}\text { Vision } \\
\text { Clarity } \\
\text { Scope }\end{array}$} & Q1: Did the project have a clear and written project objectives and vision before start? \\
\hline & $\begin{array}{l}\text { Q2: Did the project team know the importance of the project to BAM customers, and how it will fit with a } \\
\text { strategic business plan in responding to given customer's need? }\end{array}$ \\
\hline & $\begin{array}{l}\text { Q3: Were the business plan, the business perspectives and the market opportunity integrated and presented } \\
\text { to project team before start? }\end{array}$ \\
\hline & Q4: Were the project plan and its major deliverables defined or documented before start? \\
\hline & $\begin{array}{l}\text { Q5: Before start, did the project customer document for the project team the functional characteristic of the } \\
\text { product that the project is undertaken? }\end{array}$ \\
\hline & Q6: was each modification or change done in the project content documented? \\
\hline \multirow{4}{*}{$\begin{array}{l}\text { Time and } \\
\text { Cost } \\
\text { Management }\end{array}$} & $\begin{array}{l}\text { Q7: Before starting the project, did you establish its schedule and estimate the budget required for } \\
\text { achieving the goals? }\end{array}$ \\
\hline & $\begin{array}{l}\text { Q8: Before starting the system development, did you reduce the project to a set of sub-processes and } \\
\text { manageable tasks which the duration/ cost can be reasonably estimated? }\end{array}$ \\
\hline & $\begin{array}{l}\text { Q9: Was the project's manager able at any time to track and analyse costs for the work people do as well as } \\
\text { determine the remaining time to project's completion? }\end{array}$ \\
\hline & $\begin{array}{l}\text { Q10: When closing the project, were the experiences, learned lessons and project duration/cost capitalized } \\
\text { and stored for future usage and potential project estimation? }\end{array}$ \\
\hline \multirow{6}{*}{$\begin{array}{c}\text { Project } \\
\text { Quality } \\
\text { Management }\end{array}$} & Q11: Were any quality criteria or standards defined and documented before starting the project? \\
\hline & $\begin{array}{l}\text { Q12: Was the project quality regularly controlled through the project execution and were the correctives } \\
\text { actions integrated? }\end{array}$ \\
\hline & $\begin{array}{l}\text { Q13: Were any of quality assurance reviews, reports and check sheets standardized and utilized for internal } \\
\text { and external control and feedback? }\end{array}$ \\
\hline & $\begin{array}{l}\text { Q14: Did the project committee verify the project deliverable in each milestone and control if all phase } \\
\text { activities are achieved? }\end{array}$ \\
\hline & Q15: Were the test plan, Test Case Specification and the test results documented for each deliverable? \\
\hline & $\begin{array}{l}\text { Q16: When a task is realized, did the developer document or comment its content for future usage and } \\
\text { update? }\end{array}$ \\
\hline \multirow[t]{3}{*}{$\begin{array}{l}\text { Project Risk } \\
\text { Management }\end{array}$} & $\begin{array}{l}\text { Q17: Did the project manager assess before and through the project execution the internal and the external } \\
\text { events impacting the project as well as preventing necessary actions to mitigate them? }\end{array}$ \\
\hline & $\begin{array}{l}\text { Q18: Did the project manager communicate the project risks as well as their qualitative and quantitative } \\
\text { impact to all project members? }\end{array}$ \\
\hline & Q19: In analyzing the project risks, were the risks of other project developed in parallel taken into account? \\
\hline $\begin{array}{l}\text { Project } \\
\text { Human }\end{array}$ & $\begin{array}{l}\text { Q20: Did each member know his responsibility, tasks and the time required to do it before staring the } \\
\text { project? }\end{array}$ \\
\hline Resource & Q21: Were the responsibilities and task attribution of each person implied in the project documented? \\
\hline \multirow[t]{3}{*}{ Management } & $\begin{array}{l}\text { Q22: Was the resources allocation done after analysing skills and experiences required for project } \\
\text { achievement? }\end{array}$ \\
\hline & Q23: Do you feel that your efforts in the project are recognized? \\
\hline & Q24: Did you receive adequate training to perform your tasks in the project before start? \\
\hline
\end{tabular}


Table 3. Summary of questionnaire results

\begin{tabular}{|c|c|c|c|c|c|}
\hline & & No answer (\%) & Agree (\%) & Do not agree $(\%)$ & Do not know (\%) \\
\hline \multirow{6}{*}{ Vision Clarity Scope } & Q1 & 7 & 57 & 30 & 6 \\
\hline & Q2 & 7 & 77 & 10 & 6 \\
\hline & Q3 & 7 & 10 & 43 & 40 \\
\hline & Q4 & 7 & 43 & 43 & 7 \\
\hline & Q5 & 7 & 20 & 67 & 6 \\
\hline & Q6 & 7 & 13 & 73 & 7 \\
\hline \multirow{5}{*}{$\begin{array}{l}\text { Time / Cost } \\
\text { Management }\end{array}$} & Average & 7 & 36.67 & 44.33 & 12 \\
\hline & Q7 & 7 & 63 & 27 & 3 \\
\hline & Q8 & 7 & 60 & 30 & 3 \\
\hline & Q9 & 7 & 50 & 30 & 13 \\
\hline & Q10 & 7 & 10 & 80 & 3 \\
\hline \multirow{8}{*}{ Quality Management } & Average & 7 & 45.75 & 41.75 & 5.5 \\
\hline & Q11 & 7 & 17 & 67 & 9 \\
\hline & Q12 & 7 & 23 & 67 & 3 \\
\hline & Q13 & 7 & 0 & 63 & 30 \\
\hline & Q14 & 7 & 23 & 60 & 10 \\
\hline & Q15 & 7 & 40 & 50 & 3 \\
\hline & Q16 & 7 & 23 & 70 & 0 \\
\hline & Average & 7 & 21 & 62.83 & 9.17 \\
\hline \multirow{3}{*}{ Risk Management } & Q17 & 7 & 23 & 60 & 10 \\
\hline & Q18 & 7 & 23 & 47 & 23 \\
\hline & Q19 & 7 & 10 & 67 & 17 \\
\hline \multirow{7}{*}{$\begin{array}{l}\text { Human Resources } \\
\text { Management }\end{array}$} & Average & 7 & 18.67 & 58 & 16.67 \\
\hline & Q20 & 7 & 60 & 30 & 3 \\
\hline & Q21 & 7 & 30 & 60 & 3 \\
\hline & Q22 & 7 & 40 & 27 & 27 \\
\hline & Q23 & 7 & 30 & 27 & 37 \\
\hline & Q24 & 7 & 33 & 60 & 0 \\
\hline & Average & 7 & 38.6 & 40.8 & 14 \\
\hline
\end{tabular}

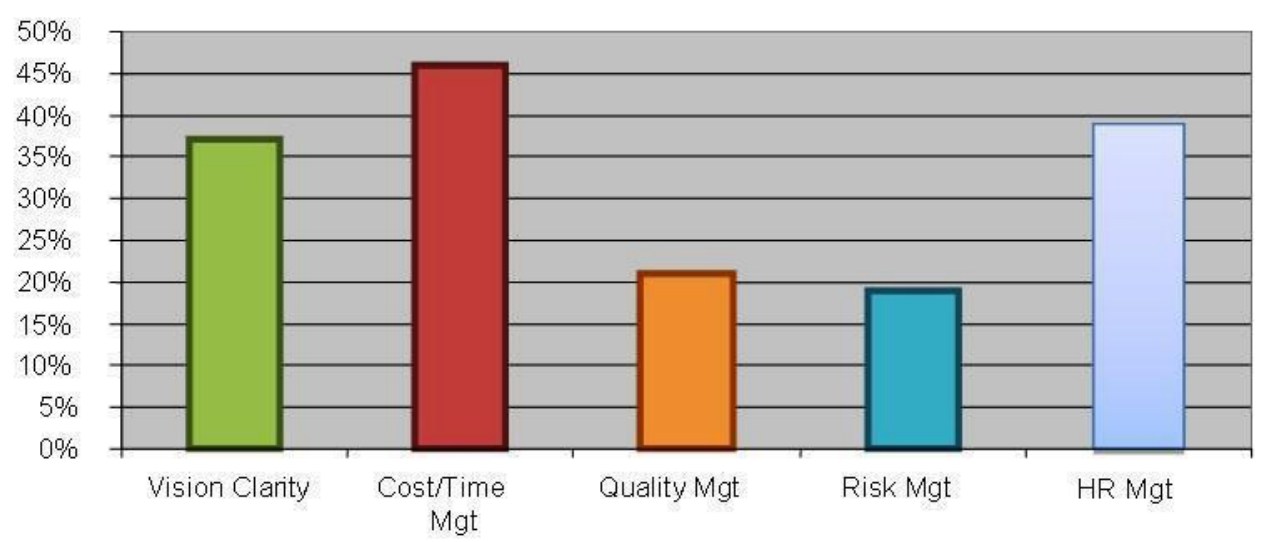

Fig. 2. Average percentage of agreement with each scope 


\section{- Quality Management Scope}

Two thirds of respondents claimed that no clear quality criteria or standards were defined before execution and that there was no monitoring process of quality during project execution. Consequently, no corrective action was taken in the quality management scope. None of the respondents $(0 \%)$ agreed with question 13 . However, $67 \%$ of respondents said that quality assurance reports and checklists are not usually used for quality control and feedback while $30 \%$ did not give any answer which may be interpreted as a lack of information about the process of reporting. $60 \%$ of respondents said that there is no continuous evaluation of all project stages and that all priority was given to completing the project. Half of the respondents said that there was no continuous documentation of quality monitoring criteria. Finally, a massive $70 \%$ of respondents denied any documentation of quality feedback after completing projects. On average, Fig. 2 shows that only $21 \%$ of the employees agree on the questions, which is very low and figure out a weakness in quality of the process.

Responses clearly show that there were serious problems in this scope. These problems have to be addressed if the company is serious in its declared ambition of getting ISO 9001/2007 certification.

\section{- Risk Management Scope}

Within the Risk Management scope, $60 \%$ of respondents said that project managers did not fully assess all events that could disrupt the project before starting and during project execution. $47 \%$ of respondents disagreed with the fact that their project manager communicated with them project risks and their qualitative/quantitative impact on project achievement. This problem was not limited to $47 \%$ but was also reflected through $23 \%$ of respondents who did not know about such communication. Two thirds of respondents claim that project managers did not take into account risk of parallel projects. It is worth mentioning here that some respondents stressed that no proper communication channels existed between the different project teams to communicate risks of projects. On average, Fig. 2 shows that only $18.67 \%$ of the employees agree on the questions, which reflects a lack of culture in term of risk taking when a project is launched.

This scope scored the lowest average agreement rate. It is clear that most projects did not have an initial risk assessment plan nor any continuous risk evaluation or communication. In top of that, risk of other parallel projects was not taken into consideration. This also has the potential of causing considerable loss in time and effort.

\section{- Human Resources Management Scope}

With the human resources management scope, $60 \%$ of respondents said that each team member knew his/her responsibility and tasks before starting. However, a similar percentage said that these responsibilities and tasks were not well documented. Only $40 \%$ of respondents said that resources are allocated after analysing skills and experiences required for achieving any given project. Moreover, $60 \%$ of respondents said they felt their effort was not being recognised. Finally, only one third of respondents agreed that they receive adequate training to perform tasks before start.
Results show that many project team members did not exactly know their responsibilities and tasks before starting and that there was a responsibility documentation problem. Many respondents also expressed their dissatisfaction with their work and complained about the lack of proper motivation and resources.

\section{Conclusions and Recommendations}

Results show that the main reasons for IT project disruptions, failure or delays are lack of clear vision and business plan, poor documentation before starting, during and after finishing projects, lack of clear quality assurance criteria, standards and reviews, and poor project risk management practices. The average acceptable performance score of all of these is below 50\%. In particular, special attention should be given to quality management and risk management scopes which scored extremely low scores ( $21 \%$ and $18.67 \%$ respectively). For other scores, it comes out that about one third of respondents find that them to be satisfactory. Only time and cost management presents a relatively higher score $(45.75 \%)$.

IT project management is not simple mathematics, it requires multifaceted skills and supportive leadership (Sidawi, 2012). A passionate project manager cannot perform alone but needs to build a team that has passion to do the project. It is clear from the results of this study that the company in concern (and likely similar public sector companies) face a serious problem with its flow of information between the different levels of employees. It is important to notice the disparities between "agree" and “disagree" in questions Q6 (13 vs. 73), Q10 (10 vs. 80) and Q19 (10 vs. 60) which reflect a significant lack of satisfaction between employees.

It is strongly recommended here that professional PM software be used for this purpose (such as MS Project or Prima Vera) and that all information and formal communications in projects be stored in the software used. Other benefits of using a software include clarifying work tasks to be done by each team member, providing IT managers with a clear overview of the employee's availability (the thing that will help them in distributing work equally among IT employees) and reducing the need for some written documents that can be lost easily. IT employees should also be trained on management (such as quality and time management) issues to increase awareness and reduce the high percentage of "do not know" responses.

Finally, it is recommended that all IT projects in public postal companies adhere to a systematic framework as suggested by Cantor (2001), Heerkens (2002) and Russel and Taylor (2002). Such a framework might include, among other issues, identifying the problem, defining the best project solution, establishing a risk analysis plan, identifying task and resource requirements, preparing a resource allocation plan and a project budget, preparing the project quality manual, preparing a test plan, maintaining communication with all team members and stakeholders and managing the project close out. It is thought that such a methodology will address most problems identified in this study and help running most IT projects smoothly.

\section{References}


Al-Otaibi, S., Osmani, M., and Price, A.D.F. (2013). A Framework for Improving Project Performance of Standard Design Models in Saudi Arabia. Journal of Engineering, Project, and Production Management, 3(2), 85-98.

Bryde, D.J., and Brown, D. (2005). The influence of a project performance measurement system on the success of a contract for maintaining motorways and trunk roads. Project Management Journal, 35, 57-65.

Cantor, M. (2001). Software leadership: A Guide to Successful Software Development. Addison-Wesley Professional, USA.

Cohen, L., Manion, L. and Morrison, K. (2000). Research Methods in Education. Routledge, UK.

Cox, R.F., Issa, R.R.A. and Aherns, D. (2003). Management's perception of key performance indicators for construction. Journal of Construction Engineering and Management, 129 (2), 142-151.

Creswell, J.W. (2003). Research Design: Qualitative, Quantitative and Mixed Methods Approaches. Sage Publications, USA.

Denzin, N.K. and Lincoln, Y.S. (2005). The Sage handbook of qualitative research. Sage Publications, USA.

ETR Technology Center (2004). Project Management Practice. ETR Technology Center, USA.

Heerkens, G. (2001). Project Management. McGraw Hill Professional, USA.

Russell, R.S. and Taylor, B.W. (2002). Operations Management. Prentice Hall, USA.

Sauer, C and Reich, BH (2009). Rethinking IT project management: Evidence of a new mindset and its implications. International Journal of Project Management, 27, 182-193.

Sidawi, B. (2012). Potential Use of Communications and Project Management Systems in Remote Construction Projects: The Case of Saudi Electric Company. Journal of Engineering, Project, and Production Management, 2(1), 14-22.

The Standish Group (2004). IT projects outcome. Chaos Chronicles, USA.

Toor, S.R. and Ogunlana, S.O. (2010). Beyond the 'iron triangle': Stakeholder perception of key performance indicators (KPIs) for large-scale public sector development projects. International Journal of Project Management, 28, 228-236.

Van Scoy, R. (1992). Software development risk: opportunity, not problem. Carnegie Mellon Institute, USA.

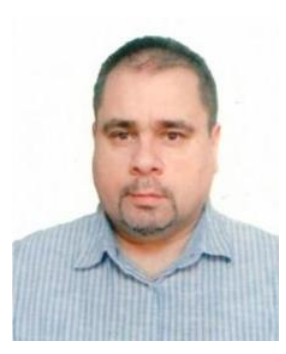

Abdelghani Bouras received the Engineering Degree in Operations Research from University of Sciences and Technology Houari Boumediene (USTHB) in Algeria, and Master and $\mathrm{PhD}$ degrees in Operations Research from Joseph Fourier University (UJF) in France. $\mathrm{He}$ is currently working as an associate professor at the Department of Industrial Engineering-King Saud University, Saudi Arabia. His research interests include combinatorial optimization, scheduling, production planning, supply chain management, project management and intrusion in networks.

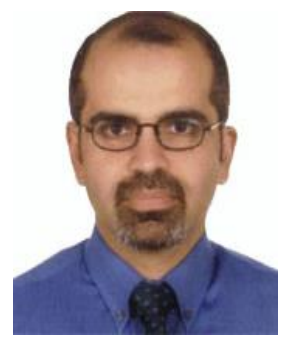

Dr. Salaheddine Bendak holds a $\mathrm{BSc}$ and $\mathrm{MSc}$ in Industrial Engineering from Middle East Technical University (Turkey), Graduate Diploma of Education from Monash University (Australia) and a $\mathrm{PhD}$ in ergonomics from $\mathrm{La}$ Trobe University (Australia). He is working currently as an associate professor at the Dept. of Industrial Engineering and Engineering Management-University of Sharjah, United Arab Emirates. He is a senior member of the Institute of Industrial Engineers and a member of the Lebanese Order of Engineers and Architects. His research interests include human factors, occupational safety and work organization. 